\title{
Study of Alcoholic Extract of Acacia Farnesiana (L.) Willd Pods
}

\author{
Revati1 K. Kadam ${ }^{1}$, Prajakata V. Khairnar ${ }^{2}$, Vijay R. Chakote ${ }^{3}$, Mahesh U. Shinde ${ }^{4}$ \\ D.O.I - 10.51201/Jusst12648 \\ http://doi.org/10.51201/Jusst12648 \\ Department of Pharmacognosy \\ 1, 2 SVERI College of pharmacy, Pandharpur, Maharashtra, India \\ Department of Pharmaceutics \\ 3-SVERI College of Pharmacy, Pandharpur, Maharashtra, India \\ Department of Pharmcology \\ 4- K.T. Patil College of Pharmacy, Osmanabad, Maharashtra, India
}

\begin{abstract}
:
Identification of bioactive compound from alcoholic extract of Acacia farnesiana leguminosae pods by using preliminary phytochemical test or thin layer chromatography and the quantification of total phenolic content by folin-ciocalteu reagent method. shade dried grounded powder of Acacia farnesiana pods was successively extracted with petroleum ether, chloroform and alcohol in soxhlet apparatus, alcoholic compound obtained in more amount as compare to other two extract so alcoholic extract was used for identification of bioactive compound. The alcoholic extract of leguminosae pods indicates the presence of major bioactive compound. Analysis of the alcoholic extract by TLC have identified naringenin from extract, and the total phenolic content in alcoholic extract was found to be $22 \%(\mathrm{w} / \mathrm{w})$. Therefore the present study deals with qualitative analysis of alcoholic extract of legumae pericarp (pod wall) of Acacia farnesiana L. In which we analyze various phytochemical which are useful for contoling various diseases TLC method used for identification of the content of naringenin from active extract of Acacia farnesiana pods. It is concluded that, legume pods contain maximum phytoconstituents or phenolic content.
\end{abstract}

KEYWORDS: Bioactive compound, Flavonoid, Naringenin, Successive soxhlet extraction, Thin layer chromatography, Acacia farnesiana 


\section{INTRODUCTION:}

The traditional herbal medicine shows substantial historical role, and this certainly true for several products that are available as 'traditional herbal medicines'. In many developing countries, an outsized proportion of the population relies on traditional practitioners and their armamentarium of medicinal plants so as to satisfy health care needs. Also modern medicine exist side-by-side with traditional practice, for historical and cultural reasons. herbal medicines have often maintained their popularity. ${ }^{1}$ A well-liked sort of healthcare of herbal medicine; even through several dif-ferences exist between traditional pharmacological and herbal treatments, herbal medicine must be tested for efficacy using conventional trial method-ology and several specific herbal extract have been demonstrated to be effi-cacious for specific condition. ${ }^{2}$ Ayurveda is one of the oldest extant health system in the world with funda-mental principles and theory based practices. The Sanskrit meaning of Ayuve-davedais science of life. Therefore. Ayurveda are based on the six darsanas, mainly the logic of Samkhya and Nyaya-Vaiseika system of philosophy. ${ }^{3}$ Practices and skills supported the theories and WHO traditional medicine is sum of the knowledge, Practices and skills supported the theories, beliefs and experiences indiginious to different cultures, whether explicable or not, used in the maintenance of health as well as in the prevention, diagnosis, im-provement or treatment of physical and menatal illness. ${ }^{4}$ Ayurveda is an ancient science of life originated from Vedas, Vata, Pitta and Kapha are to be considered as the primary and essential constitutional factors of the human body. These fundamental factors maintain the integrity of the human body. Disequilibrium of these three basic doshas may bring about the dissolution of the body or cause its death, while their equilibrium cause is well-being. ${ }^{5}$ Acacia farnesiana L.Willd (synonym Vachellia farnesiana) grown in India, it is indigenous to the India in Tropical Burma, Sri Lanaka, Saudi Arabia, Egypt and Africa. In India it is mostely found in Maharashtra, Gujarat, Andhra Pradesh and Karnataka. It is used by local people, against various treatment like cold and cough. Ayurveda relatively proved to be efficacious in treatment of skin diseases. Shodhana and Shamana are two important therapies that can be adopted in these conditions. To remove the aggravated doshas locally Lepa is considerd to be the best form of treatment. Hence lepa was selected as the mode of treatment. In pathology of Vyanga vata, pitta and rakta are vitiated doshas and improves the complexion should be considerd while treating. ${ }^{6}$ India has widely distributed throughout the country because of rich flora. Herbal medicines are the idea of treatment and cure for various diseases and 
physiological conditions in traditional methods practiced such Ayurveda, Unani and Siddha. Medicinal components from plants play a crucial role in conventional also as western medicine. Plant derived drugs have been a part of the evaluation of human, healthcare for thousand of years. Plant based drugs were commonly used I India and China. Today a considerable number of medicine are developed from plants which are active against variety of diseases. The isolation of the active ingredients (chemical compounds) found during a particular medicinal plant and its subsequent modification. ${ }^{7}$. Acacia farnesiana Acaciafarnesiana (leguminosae Mimosoideae) is commonly known as babul tree the species genus Acacia has been knwn to contain a number of groups, based on molecular and morphological studies that have required division into at least five genera (Acacia, Senegalia, Genus ' $\mathrm{X}$ ', Acaciala, Racoperma). The currently recognized genus Acacia comprises of 163 species, 133 in Africa and the Americas, 36 in Asia and 11 species in Australia. These species of Acacia consist mostly of shrubs and small tress and their ranges extend from cool to tropical regions. Acacia is often a dominant trees or shrub in tropical and subtropical woodlands, savannas, and also oc-cur in the temperate regions of the world. [08] Acacia has medicinal plant that grows in tropical parts of Indian subcontinent, particularly in sandy soils of river beds in Northern India and parts of Tamil Nadu. Tree, $8 \mathrm{~m}$ tall, bark brown, or rough branches, purplish to gray, with very small glands, stipules spin scent, usually short, up to $1.8 \mathrm{~cm}$ long, rarely longer, never inflated, leaves twice pinnate, flowers in axillary pedunculate heads. A farnesiana features a great number of uses in traditional medicine. The bark has medicinal properties and is employed to treat cough and as an astringent, in java cassie flower used as an emetic and by woman childbirth. Leaves are used in ulcers and sores, roots are chewed for sore throat and in decoction. The green fruit is very astringent and in decoction it is employed against dysentery and inflammation of the skin. The pulp of pods is used as a purgative. Various chemical constituent are present in pods like gallic acid, ellagic acid, methyl gallate, kaempferol atomedendr in and naringenin. ${ }^{9}$ The flowers of Acacia farnesiana used for production of cassie perfume it occurs in loose, sandy soils of river beds almost all over India. The leaf of this plant is used for gonorrhea. The bark can be used as astringent or demulcent, the wood is hard which is used for medicinal purpose, gummy roots of this plant chewed for soar throat and the roots are also used for diarrhea, stimulant, asteingent.Various different species of Acacia are present like (Acacia nilotica, Acacia polycantha, Acacia leucophala) which shows the medicinal importance. In the present paper the different extract obtained from the pods of Acacia 
farnesiana exhibited a bioactive compound. The pods are very characteristic, beaded necked which are fleshy, slightly curved, blackish when mature, long and dull brown in colour, pods size $5.0-7.5 \mathrm{~cm}$. The pods of Acacia farnesiana which contain various polyphenolic compound (gallic acid, Kaemferol, aromadendrin and naringenin) also tannis are found in pods of Acacia farnesiana. $^{1-3}$

\section{PLANT PROFILE}

Synonyme: Sweet acacia, Vachellia Farnesiana

Biological source: It consist of shrubs and small trees of Acacia farnesiana belongs to family Leguminosae

Geographical source: Acacia farnesiana found in India, it is indigenous to the India in Tropical Burma, Sri Lanaka, Saudi Arabia, Egypt and Africa. In India it is mostly found in Maharashtra, Gujarat, Andhra Pradesh and Karnataka.

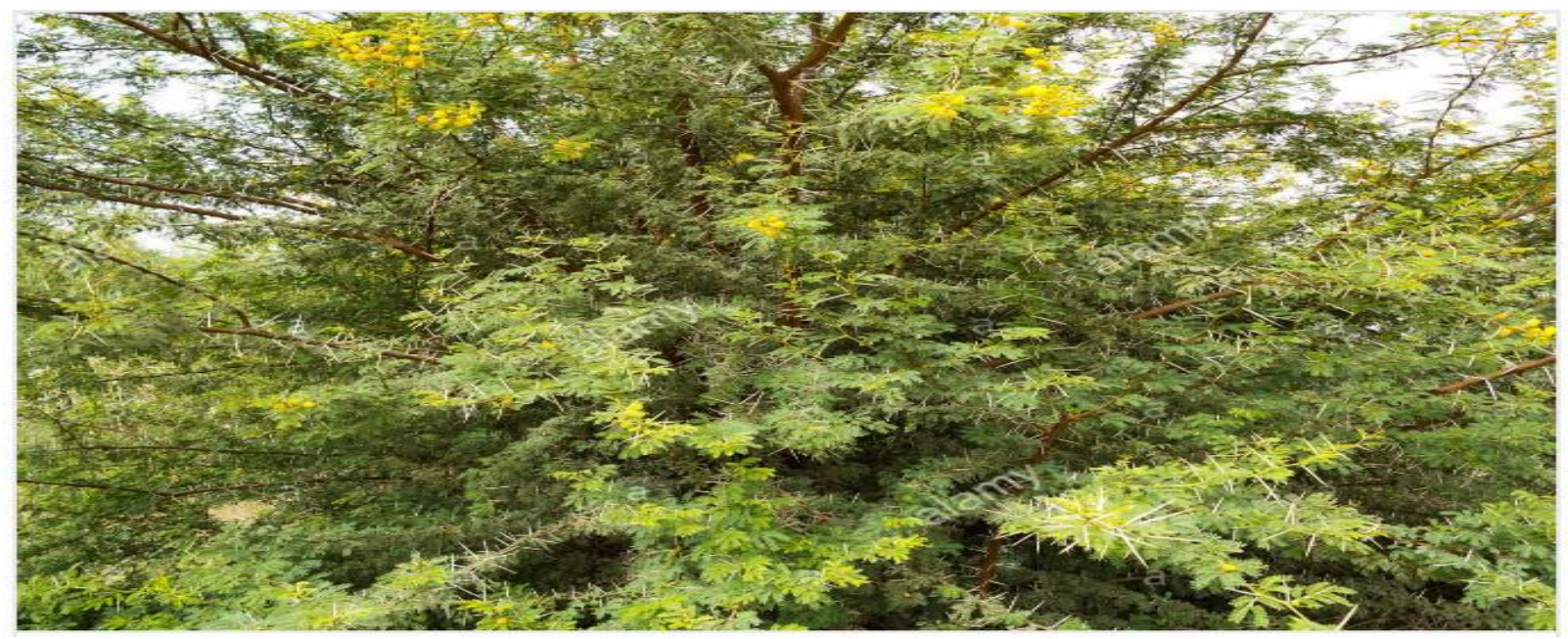

Fig no.1 Acacia farnesiana L. plant

Description: Acacia farnesiana is described as spreading shrub mostely $1.5-4 \mathrm{~m}$ high, bark smooth or finely fissured, grey-brown, leaves with petiol $0.2-2 \mathrm{~cm}$ long, hairy especially above, with a circular to elongated gland, occasion-ally with a sugary gland apex, interjugary glands absent. globose heads, 33-95-flowerd, yellow or orange, 1-3 axil of leaves, peduncles mostly 3$30 \mathrm{~mm}$ long hairy. Pods cigar-like, straight to strongly curved, terete, turgid, $1.5-8.5 \mathrm{~cm}$ long, 8 $17 \mathrm{~mm}$ wide, dark brown to blakish, glabrous, seeds transeverse or oblique, separated by pith. 
Chemical constituent: Pods containing various polyphenols i.e gallic acid, ellagic acid, m-digalic acid, methyl gallate, kaempferol, aromadendrin, and naringenin, also the seed of A. farnesiana are rich source of amino acid, such as, lysine, arginine, glycine and histidine etc.

\section{Uses:}

Bark: bark is used as astrigent and demulcent. It is used in the treatment of coughs, a decoction of the bark is used as a bath in the treatment of ty-phoid. The juice of the bark is applied topically to treat swellings, bleed-ing gums etc.

Roots: roots have been chewed as a treatment for soar thoroat. A decoc-tion of the root is used as a remedy for tuberculosis. A decoction of the gum from the trunk has been used in the treatment of diarrhea.

Flowers: flowers have been used as an antispasmodic, emetic, stimulant and stomachic. They are taken by women in java after giving birth. An in-fusion is used in the treatment of dyspepsia and neuroses. A decoction is used to treat a prolapsed rectum, and is taken as an injection in the treatment of leucorrhoea. distillation process is used to produce a perfume from the flowers called cassie.

Leaves: leaves used for gonorrhea. The powderd dried leaves have been applied externally as a treatment for wounds. A decoction of the leaves is used as a wash to treat ulcers and sores, after which the young leaves, are then applied as a poiltice

Pods: is used as purgative. The green seedpods are very astringent. A de-coction has been used in the treatment of dysentery and has been used in the treatment of the skin and mucous membranes. An infusion of the pods has been used in the treatment of soar throats, diarrhea leucorrhoea, conjunctivitis and uterorrhagia.

\section{MATERIAL AND METHOD:}

\section{Identification of plant material}

Pods of Acacia farnesiana L. Willd locally known as Devbabul were collected from Lavang, Solapur district, Maharashtra, during Augest. A specimen was authenticated by Botanical Survey Of India, Western Reginal Centre, Koregaon road, Pune. 


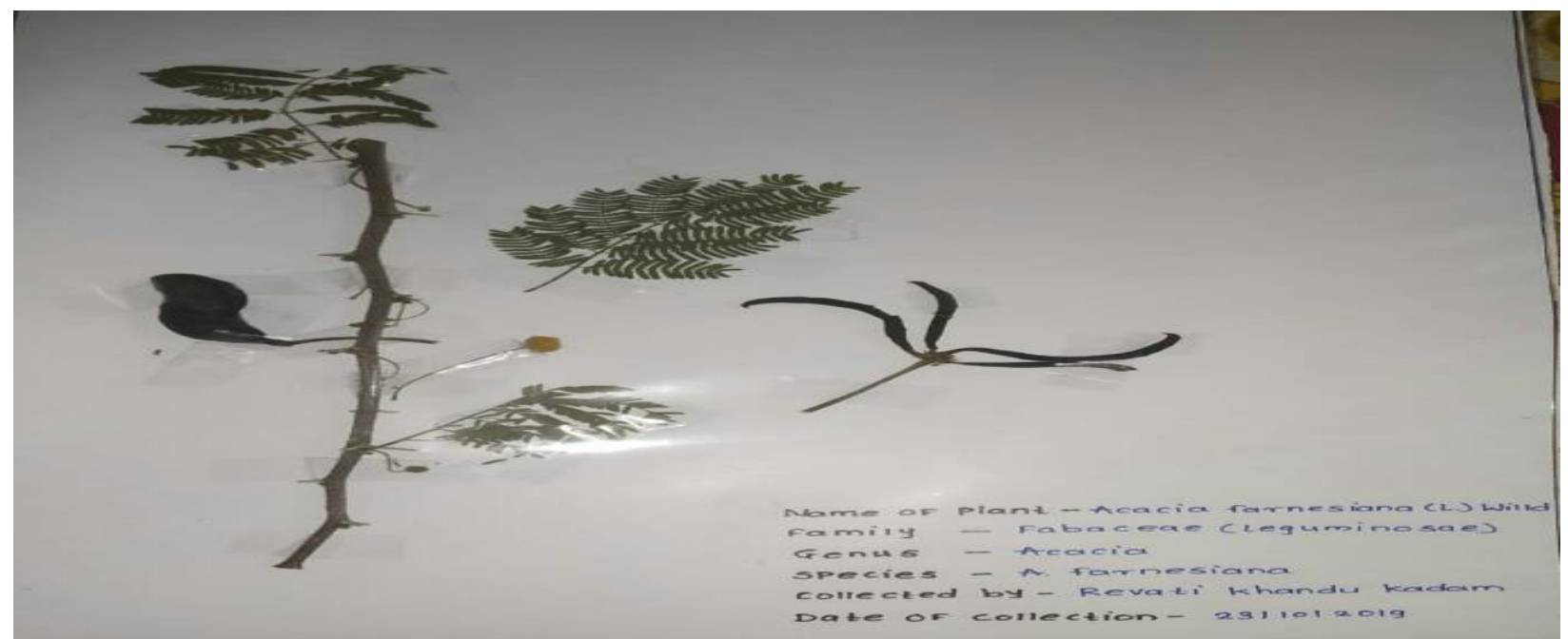

Fig no. 2 Herbarium of Acacia farnesiana $\mathrm{L}$.

Drying and grinding of plant material of A. farnesiana L. pods: The plant of A. farnesiana L. pods was collected dried in sunlight and suect-ed for grinding into coarse form.
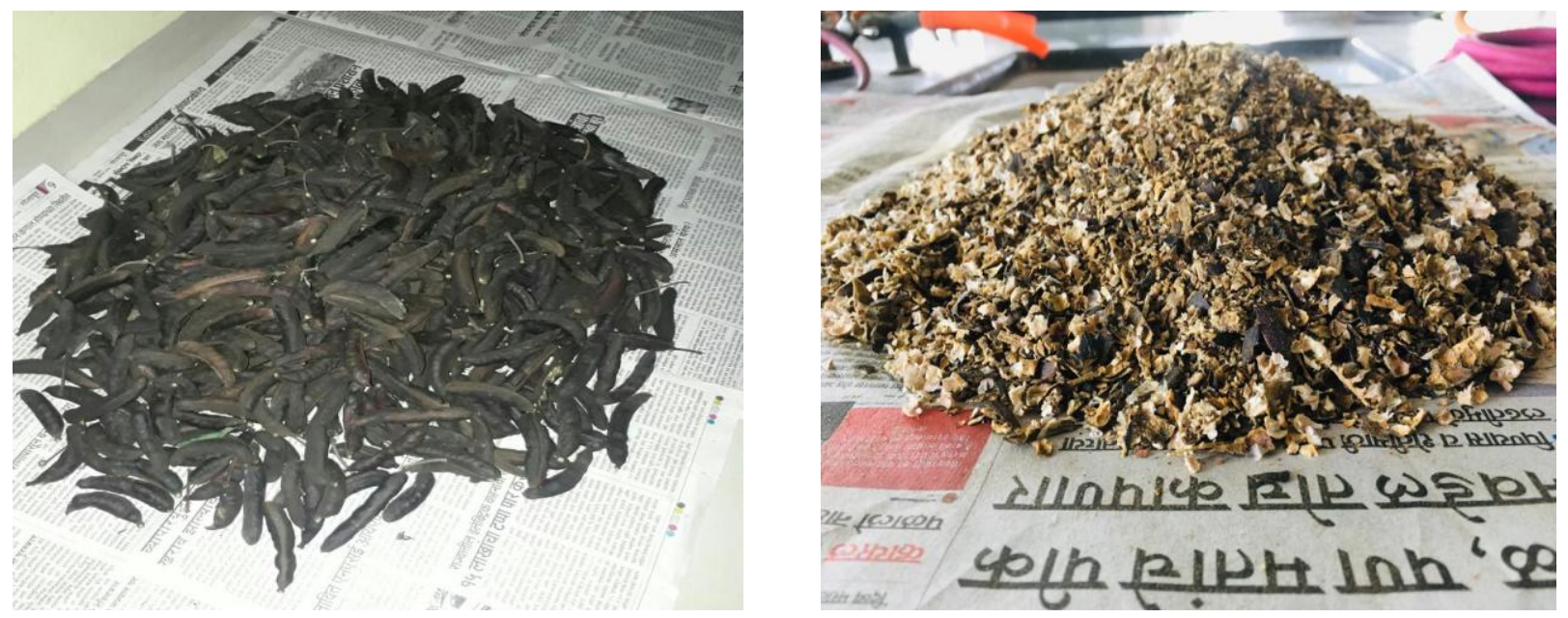

Fig No. 3 Drying and grinding of $A$. farnesiana L. pods

\section{Pharmacognostic study:}

Determination of Morphological character of $\boldsymbol{A}$. farnesiana L. Morphology is the study of the form of an objective while morphology is the description of that form where the material is known to occur in a particular form. Morphological and organoleptic characters viz., colour, odor, taste, shape and size were observed and evaluated botanically 


\section{Drug profile:}

Synonyme : Naringetol, Salipurpol

Category : Antioxidant, Anti-inflammatory

Mono isotopic mass : $272.068473 \mathrm{~g} / \mathrm{mol}$

Subcategory : MNP

IUPAC Name : (5, 7- Dihydroxy-2-(4-hydroxyphenyl) chroman-4-one)

$\log P$ : 2.4

\section{Chemical structure:}

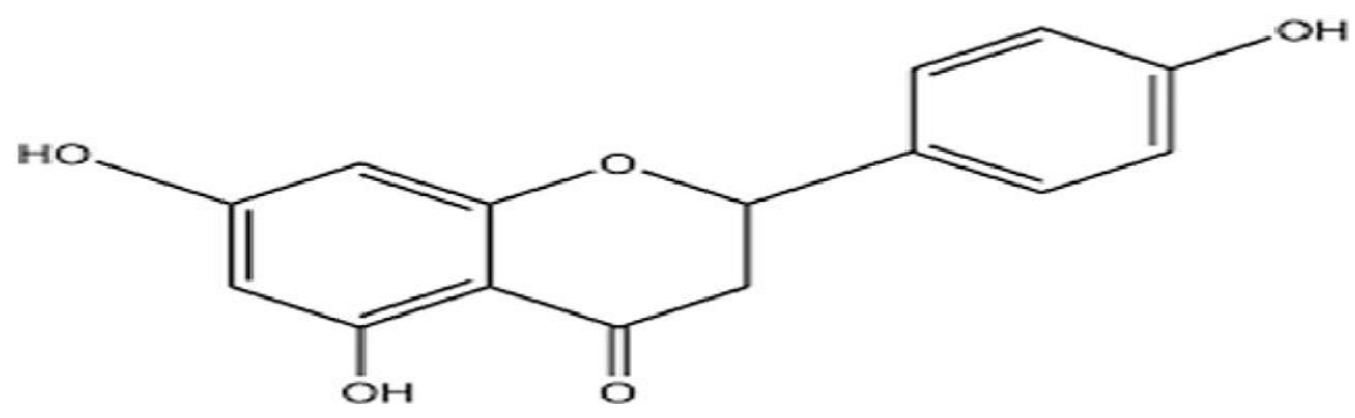

Fig.No.4 Basic structure of Naringenin

\section{Physicochemical study}

\section{Determination of Ash value of pods of A. farnesiana L.}

The ash remaining after ignition of medicinal plant material is determined by three different methods which measures total ash, acid-insoluble ash and wa-tersoluble ash.

\section{Determination of Total ash of A. farnesiana $\mathrm{L}$.}

Marerial required: Furnace, silica crucible, powder of pods, weighing balance.

Procedure: Weigh about $2 \mathrm{~g}$ of air-dried powder drug; taken in tared silica crucible. The material was incinerated gently at first and then gradually increasing the temp. not more than 
$450^{\circ} \mathrm{C}$ until free from carbon. It was kept in desicator for cooling and weighed. The percentage w/wof ash with reference to the air-dried plant material was calculated.

\section{Determination of Acid-insoluble ash of A. farnesiana $\mathbf{L}$.}

Material required: Furnace, silica crucible, weighing balance, ash less filter paper, 2M HCL, powder of AF.

Procedure: The total ash was boiled with $25 \mathrm{ml}$ of $2 \mathrm{M} \mathrm{HCL}$ for $5 \mathrm{~min}$, and filtered and collected the insoluble matter on ash less filter paper. Then it was washed with water, and ignited in tared crucible for $15 \mathrm{~min}$ at a temp. not exceeding $450^{\circ} \mathrm{C}$. it was kept in desicator for cooling and weighed. The percentage w/w of acid insoluble ash with reference to the air-dried plant material was calculated.

\section{Determination of Water-soluble ash of $A$. farnesiana $L$.}

Material required: Furnace, silica crucible, weighing balance, ashless filter paper, powder of pods $\mathrm{AF}$, hot water.

Procedure: Total ash obtained was boiled for five minutes with $25 \mathrm{ml}$ of diluted water, coled and collected the insoluble matter on an ash less filter paper, washed with hot water and ignited for 15 min. at temperature not exceeding $450^{\circ} \mathrm{C}$. substractes the weight of the insoluble ash. The percentage of water-soluble ash was calculated with reference to the air-dried plant material was calculated.

\section{Extraction of pods of $A$. farnesian $\mathrm{L}$.}

\section{Successive Soxhlet extraction:}

Material required: Petroleum ether, chloroform, alcohol, soxhlet apparatus, periplates, rotary evaporator, heating mental, RBF.

Principle: Soxhlet extractor is used for extraction. The fat extractor uses the solvent re-flux and siphone principle to continuously extract the solid matter by pure solvent, which saves the solvent extraction efficiency and high efficiency. The solid material is ground prior to extraction to increase the area of solid-liquid contact. The solid material is then placed in an extractor. The bottom flask containing a solvent, and is connected to are flux condenser. The bot-tom flask is 
heated to boil the solvent, the vaporizes through the branch pipe of the extractor, and the solvent is contacted with the solid for extraction. When the solvent surface exceeds the highest point of the siphon, the solvent containing the extract is siphoned back. The flask, thus extracting portion of the solid material, is repeated such as a pure solvent and the extracted material is concentrated in the flask.

Procedure: The Acacia farnesiana L. pods was shade dried at room temperature and $50 \mathrm{~g}$ of coarse powder each batch was successively extracted with petroleum ether, chloroform and alcohol respectively in increasing order of polarity. The ex-tract were concentrated under reduced pressure using Rotary evaporator. Af-ter drying, the respetive extract were weighed and percentage yield was calculated.

\section{Preparation of alcoholic extract}

The pods were sun dried for 3-4 days. The dried pods $(50 \mathrm{~g})$ were grounded to coarse powder using mixer extraction was performed by successive soxhlet extraction with prtroleum ether, chloroform and alcohol. The alcoholic extract were filtered (whatmann filter paper no.1) and dried under rotary evaporator.

\section{Chemicals:}

The biomarker naringenin was purchased from Sigma Aldrich, while LR grade chemicals viz., alcohol, chloroform and petroleum ether purchased from science direct chemicals Nashik, India.

\section{Phytochemical screening of A. farnesiana L. pods alcoholic extract:}

1. Preliminary phytochemical screening: One gram of alcohol extract was taken in test tube and dissolve in alcohol and then following test were performed.

\section{A. Test for alkaloids}

- Dragendroff 's test: To the extract solution, add few drops of Drangendroff 's reagent, reddish precipitate indicate presence of alkaloid

- Mayer's test: To the extract solution, add few drops of Mayer 's reagent, creamy white precipitate indicate presence of alkaloid. 
- Wagner's test: To the extract solution, add few drops of Wagner 's reagent, reddish brown precipitate indicate presence of alkaloid.

\section{B. Test for flavonoids:}

- Shinoda test: $2 \mathrm{ml}$ of solution was taken in test tube and to it magnesium powder and few drops of conc. HCL were added which gives pink colour, indicates presence of flavones.

- Sulphuric acid test: $2 \mathrm{ml}$ solution was taken in test tube and to it add sulphuric acid $(66 \%$ or $80 \%)$ which gives deep yellow colour, indicates presence of flavones.

- Lead acetate solution: $2 \mathrm{ml}$ solution was taken in test tube and to it add small quantity of lead acetate solution which gives yellow colour precipitate, indicates presence of flavones.

\section{Test for glycosides:}

- Keller-killiani test: $2 \mathrm{ml}$ solution was taken in test tube add glacial acetic acid, 1 drop of 55 ferric chloride and conc. $\mathrm{H} 2 \mathrm{SO} 4$ reddish brown colour appears junction of the two liquid layers and upper layer appear bluish green colour, indicates presence of glycoside.

\section{Test for proteins:}

- Million's test: Extact solution $+2 \mathrm{ml}$ of Million's reagent white precipitate appears, which turn red upon gentle heating, indicates presence of protein.

\section{E. Test for steroids:}

- Salkowski's test: Treat extract with chloroform and add few drops of conc. Sulphuric acid, shakeand allow to stand for sometime, red colour appears in the ;ower layer indicates the presence of steroids and formation of yel-low colored lower layer indicating the presence of terpenoids.

- Libermann-Burchard test: Extract treated with few drops of acetic anhydride , boil and cool, con-centrated sulphuric acid is added from the side of the tube, a brown ring at 
the junction of two layer and the upper layer turns geen indi-cates the presence of sterols and formation of deep red colour indicates the presence of triterpenoids.

\section{F. Test for tannis:}

- Ferric chloride test: Extract solution gives blue-green colour precipitate with $\mathrm{FeCl}_{3}$.

- Acetic acid test: Extract solution gives red colour precipitate with acetic acid.

\section{Phytochemical analysis:}

Qualitative preliminary phytochemical analysis were done using procedures of Kokate, for identification of various phytochemical constituents furthermore thin layer chromatography for detection of naringenin from alcoholic extract of Acacia farnesiana linn.Willd.7

\section{Thin Layer Chromatography:}

For identification of flavonoids by TLC a small amount of alcoholic extract (1mg extract dissolve in $1 \mathrm{ml}$ methanol) are manually applied on TLC plate along with standard samples of naringenin $(1 \mathrm{mg} / 1 \mathrm{ml})$ using capillary tubes, plate developed in Toluene: ethyl acetate: formic $\operatorname{acid}(50: 40: 10)$. The detection of the spots under the UV at $254 \mathrm{~nm}$ and $366 \mathrm{~nm}$ by using NP reagent.

\section{Determination of total phenolic content:}

The total phenolic content in alcoholic extract of Acacia farnesiana pods was measured using folin ciocalteu method poly phenol gives blue colour chromogen in alkaline medium with folin ciocalteu method. From standard stock solution (100micro g/ ml) different concentration and incubated for $10 \mathrm{~min}$ after that $4 \mathrm{ml}$ of sodium carbonate was added and finally incubated for $2 \mathrm{hrs}$ (keep in dark place) and absorbance was taken against blank at 740nm galic acid was used as standard to produce the calibration curve. Total phenolic content was expressed in $\mathrm{mg}$ of galic acid equivalents (GAE/g of PFVF). ${ }^{12}$ 


\section{RESULT:}

\section{Phytochemical analysis:}

Successive soxhlet extraction values of pods powder percentage yield of petroleum ether, chloroform and alcohol extract was found to be $0.24 \%, 0.34 \%$ and $27.94 \%$ respectively. Qualitative preliminary phytochemical analysis of alcoholic extract was performed which contain various different compound like alkaloids, flavonoids, glycoside, proteins, steroid, tannis.

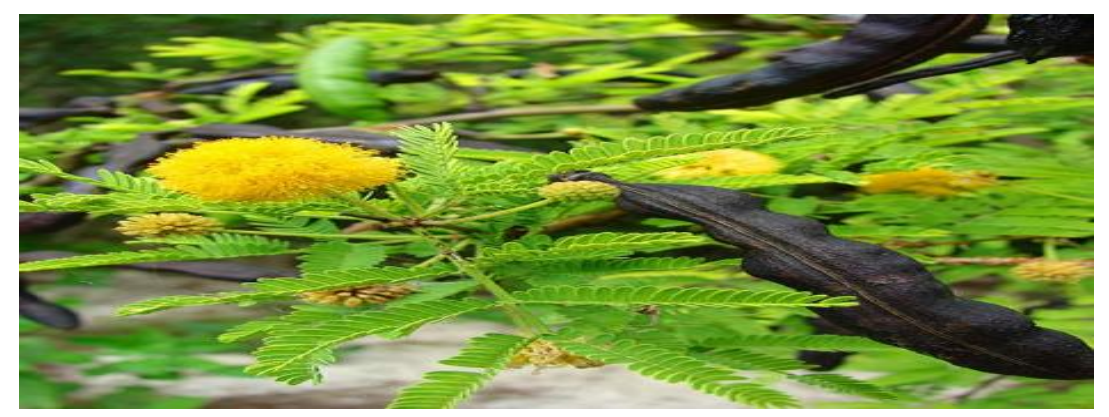

Fig . no 5 Acacia farnesiana plant

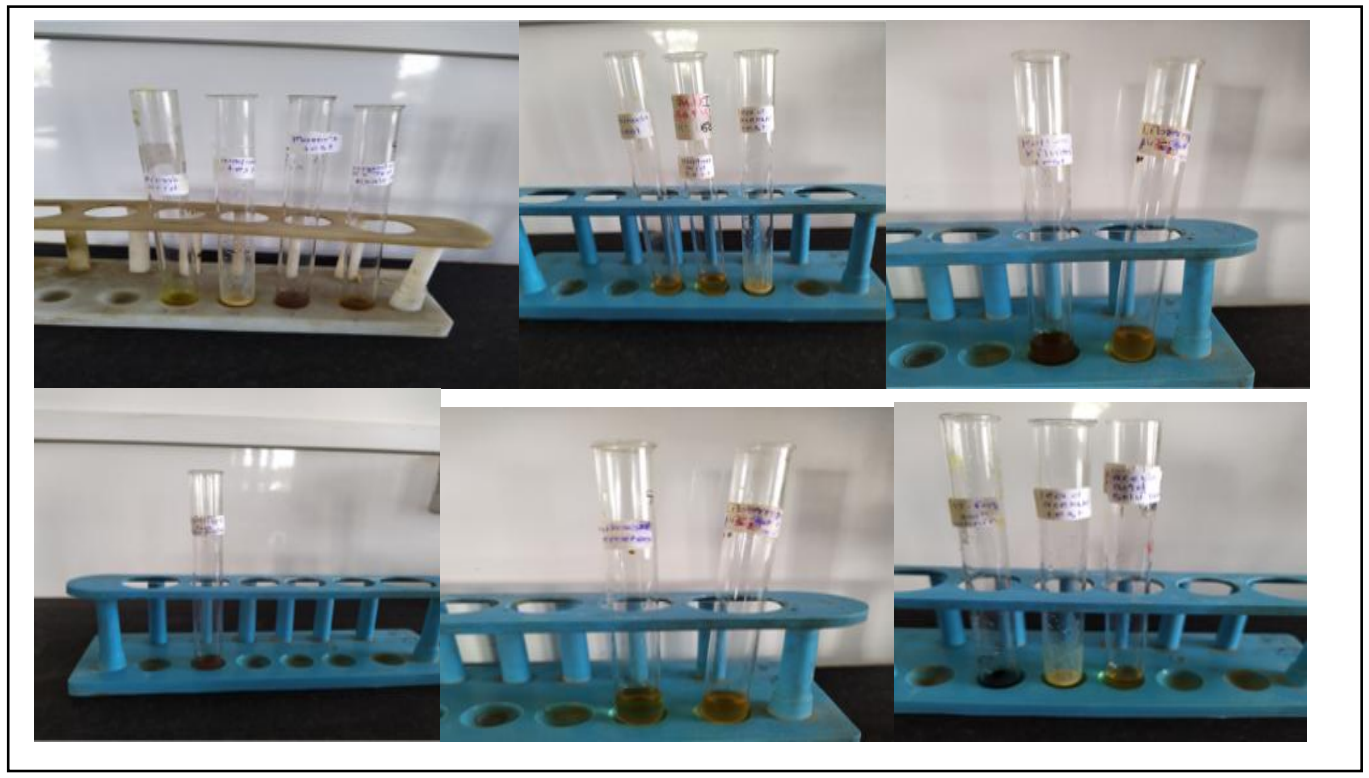

Fig no. 6 Preliminary phytochemical test of alcoholic extract of Acacia farnesiana 


\section{Thin layer chromatography:}

Thin layer chromatography of alcoholic extract was performed to identify the naringenin in extract five spots were found in alcoholic extract $(0.06,0.10,0.23,0.26,0.4)$ under day light in Toluene:ethyl acetate:formic acid(50:40:10)

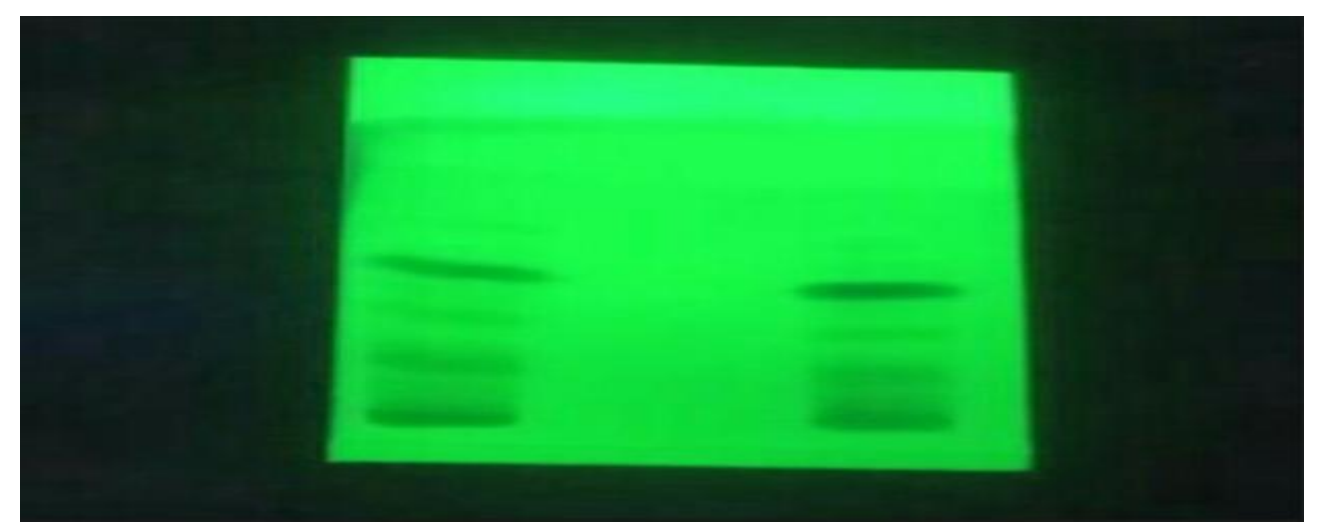

Fig 7: TLC of Acacia farnesiana pods

\section{Determination of total phenolic content:}

Total phenolic content in $10 \mathrm{mg}$ alcoholic extract of Acacia farnesiana pods was found to be $22 \%$ $(\mathrm{w} / \mathrm{w})$ using the standard curve of galic acid $(\mathrm{R} 2=0.9844)$

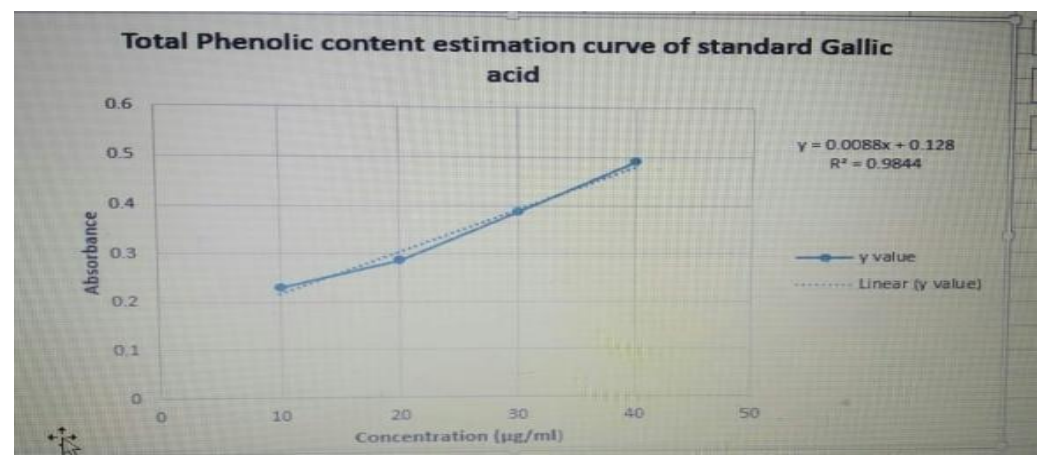

Figure No.8: Total Phenolic content estimation curve of standard galic acid. DISCUSSION AND CONCLUSION:

The data indicate that the active alcoholic extract of Acacia farnesiana content various different preliminary phytochemicals like alkaloid, flavonoids, glycoside, proteins, steroid, and tannin, 
also thin layer chromatography was used for identification of naringenin in alcoholic extract that shows green spot and this spot compare with standard naringenin. The total phenolic content estimation of alcoholic extract by using galic acid as standard was done which shows the calibration curve at $740 \mathrm{~nm}$ and total phenolic content was expressed in $\mathrm{mg}$ of galic acid equivalent $(\mathrm{GAE}) / \mathrm{g}$ of PFVF

The Acacia farnesiana pods cntain various bioactive compound and they shows various different biomarker in extract.

\section{ACKNOWLEDGEMENT:}

The authors are thankful to the MGV's College of pharmacy, Savitribai Phule Pune university, for providing necessary facilities during the experiment and also supporting this work.

\section{CONFLICT OF INTEREST:}

The authors declare no conflicts of interest with findings from this study.

\section{REFERENCES:}

1. H. Ibrahim Erkovan, Peter j. Clarke, Ralpha D.B. Whalley. A review on general description of Vachellia farnesiana (L) wight and Arn. J.of the agricultural faculty,47(1):71-76, 2016.

2. Deshmukh sp, Shrivastava B and Bhajipale NS. A review on Acacia species of therapeutics importances. vol.6, issue 4,; Jully-August;2018;24-34.

3. Nurul Iman Suansa, Hamad A, Al-Mefarrej.Ameliorative effect of shade on seedling growth. American journal of plant sciences, 2019,10,12-23.

4. Sumit Kumar, Naringenin: present status and its future prospective Int.J.Pharm. Phytopharmacol. Res. 2015, 5(1):18-26.

5. Sumathi R, Tamizharasi S. and Sivakumar T. Bio- Dynamic activity of naringenin-A review. ISSN vol 4, issue 8, PP 234-236 August 2015.

6. Mauricio M. Victor, Jorge M. David, Maria C. K. Sakukuma, Elivana L. Franca and Anna V. J. Nunes. A simple and efficient process for the extraction of naringin from grapefruit peel waste gps-2017-0112. 
7. Sanjay Biradar, Bhagyashri Rachetti. Qualitative analysis of legume pericarp (pod wall) and seeds of Acacia farnesiana L. vol 6, issue B, May-Jun 2013, PP 43-46.

8. Konrad Habelt and Fritz Pittner. A rapid method for the determination of naringin, pruning and naringenin applied to the assay of naringinase. Analytical biochemistry 134, 393-397(1983).

9. Salfarina Ramli, Ken-ichi Harada, Nijsiri Ruangrungsi. Antioxidant, antimicrobial and cytotoxicity acticities of Acacia farnesiana $(L)$ willd leaves ethanolic extract. Pharmacognosy journal july 2011 vol 3, issue 23.

10. Thirupal Reddy B, Varaprasad Bobba Rala and D. Ali Moulali. Antimicrobial screening of Acacia farnesiana (L) willd. Ind. J. Bot. Res. 2008 vol 4 (2): 249-251.

11. Bruce R. Maslin, Boon Chuan Ho, Hang Sun, Lin Bai. Revision of senegalia in china and notes on introduced species of Acacia, Acaciella, Senegalia and Vachellia (leguminosae: mimosoideae), plant diversity. 2019. 09. 001.

12. Rudrappa Nandeesh, Sachidananda Vijayakumar, Abhinandan Munnolli, Ambika Alreddy. Bioactive phenolic fraction of Citrus maxima abate lipopolysaccharide-induced sickness behavior and anorexia in mice: In-silico molecular docking and dynamic studies of biomarkers against NF-Kb, Biomedine and Pharmacotherapy journal 2018, 1535-1545

13. Perwez Alam, Mohammad K. Parvez, Ahmed H. ARBAB and Mohammed S. Al- (2017) Dosari, "Quantitative analysis of quercetinrutin, naringenin or gallic acid by using validated RP-and NP-HPTLC methods for the quality control of anti-HBV and active extract of guiera senegalensis, vol. 55, No.1, 1317-1323.

14. Chung Ting-Wen, Li Shiming, Lin Chi-Chien, Tsai Sen-Wei, (2019) “ Antinocipative and antiinflammatory effects of citrus flavonone naringenin 32(2); 81-85

15. Sharma Kavita, Mahato Neelima, Lee Yong Rok (2018) “Extraction, characterization and biological activity of citrus flavonoids", 1-11.

16. Cordenonsi Leticia M., Sponchiado Rafaela M., Campanharo Sarah C., Garcia Cassia V. (et.al) (2017) "Study of flavonoids present in pomelo (citrus maxima) by Dsc, UV-VIS, IR, $1 \mathrm{H}$ and $13 C$ NMR and MS" 01, 31-37. 
17. Rajamani Sumathi, Tamilarazi Sengadon, Radhakrishanan Arun, Shanmukhan Nikhitha (2018) “ Pharmacokinetic and tissue distribution of naringenin and naringenin nanosuspension, 12(4) S1201-207.

18. Khoddami Ali, Meredith A., Roberts Thomas H., (2013) “ Techniques for analysis of plant phenolic compounds", 18, 2328-2375.

19. Sara Gabr, Stefanie Nikles, Eva Maria Prerschy Wenzing, Karin Ardjiomand-Woelkart et.al (2018) "Characterization and optimization of phenolics extracts from Acacia species in relevance to their anti-inflammatory activity, Biochemica systematic and ecology 78, 21-30.

20. Jadhav Aruna P, kareparamban Joseph A, Nikam Pravin H, Kadam Vilasrao J (2012), "Spectrophotometric estimation of Ferulic acid from Ferula asafetida by Folin-Ciocalteu's Reagent” Der Pharmacia Sinica, 3(6): 680-684. 